\title{
Feces, flies, and fetor: Findings from a Peruvian shantytown
}

\author{
Sharon R. A. Huttly, ${ }^{1}$ Claudio F. Lanata, ${ }^{2}$ Beth A. C. Yeager, ${ }^{2}$ \\ Mary Fukumoto, ${ }^{2}$ Roberto del Aguila, ${ }^{2}$ and Carl Kendall ${ }^{3}$
}

\begin{abstract}
Sanitary disposal of feces is vital to combat childhood diarrhea, and its promotion is key to improving health in developing countries. Knowledge of prevailing feces disposal practices is a prerequisite to formulation of effective intervention strategies. Two studies were conducted in a shantytown area of Lima, Peru. First, information was gathered through in-depth interviews with mothers and structured observations (4 hours) of young children and their caretakers. Data on beliefs and practices related to feces disposal behaviors were obtained. Excreta were deposited by animals or humans in or near the house in $82 \%$ of households observed. Beliefs about feces depended on their source and were reflected in how likely the feces were to be cleared. While $22 \%$ of children aged $\geq 18$ months were observed to use a potty for defecation, $48 \%$ defecated on the ground where the stools often remained. Although almost all children were cleaned after defecation, 30\% retained some fecal matter on their body or clothes. Handwashing after the child's defecation was extremely rare for both children (5\%) and caretakers (20\%). The hygienic disposal of feces poses problems in this type of community. Nevertheless existing practices were found that show promise for promotion on a wider scale, including greater use of potties.
\end{abstract}

Rapidly increasing numbers of urban poor pose serious challenges for developing country governments and aid agencies. Among these are the health impacts of environmental conditions encountered in densely populated shantytowns. Typically in these settings, access to clean water and ade-

1 London School of Hygiene and Tropical Medicine, Maternal and Child Epidemiology Unit, United Kingdom. Mailing address: Sharon R. A. Huttly, Maternal and Child Epidemiology Unit, London School of Hygiene and Tropical Medicine, Keppel Street, London, WC IE 7HT, UK. Email: s.huttly @lshtm.ac.uk

2 Instituto de Investigación Nutricional, Research Division, Lima, Peru.

3 Department of International Health and Development, Tulane University, New Orleans, U.S.A. quate sewage disposal is limited or nonexistent. Provision of clean water and sewerage have been singled out as crucial preventive strategies against childhood diarrhea (1). Yet even though some shanty communities have resources for improving infrastructure, existing technologies are not appropriate for many shantytowns. For example, pit latrines are often not feasible where housing density is extremely high, or where the terrain is unsuitable, such as rocky ground which makes digging pits difficult or impossible.

The World Health Organization encourages promotion of sanitary disposal of feces as a key water-related behavior to improve health (2). To for- mulate an effective behavioral intervention strategy, it is essential to know about prevailing feces disposal practices and their determinants. Yet surprisingly little is known, except that even where latrines and other sanitary hardware are available, young schoolchildren rarely use them, and feces are frequently observed in the environment.

Canto Grande is a shantytown typical of those found in the rocky hill area around Lima. Because Lima has no rainfall, Canto Grande receives its water by cistern truck except in some areas, where water is pumped in twice weekly through recently laid pipes. The disposal of feces is problematic. Young children suffer very high rates 
of diarrhea: on average, nine episodes per year among those aged $<3$ years (3).

We previously reported the results of 10-hour structured observations in 62 families of one sector of this community (4). In brief, the findings were that young children often defecated indiscriminately around the home area, feces were frequently left accessible to children, and handwashing after defecation was very rare. However, when potties were used, they were frequently emptied into a basic latrine. To extend these findings, we here present data from two research initiatives conducted in other parts of Canto Grande. The first was a detailed ethnography and structured observations that were carried out in 1988. This study covered a wide range of hygienerelated beliefs and behaviors, including information-albeit limited in detail-pertaining to the disposal of feces. The second research initiative was undertaken using the results of the first. It consisted of new in-depth interviews and structured observations to obtain more detailed information as a preliminary phase for an intervention study to improve feces disposal practices.

\section{MATERIALS AND METHODS}

\section{Research Initiative \#1}

The ethnographic component of this initiative was conducted in four sectors of Canto Grande, chosen on the basis of the circumstances of their founding (whether they originated in "invasion" or were authorized by the government) and the level of community organization. Six local anthropologists interviewed 120 mothers of young children between September 1987 and December 1988. They used two sets of guides. One was general, aimed at gathering data on common behaviors and practices within a broad range of issues related to hygiene and nutrition as well as community characteristics. The second was more specific, seeking determinants of the common practices and exploring issues related to a planned intervention. The mothers were selected on the basis of their knowledge concerning these issues and their rapport with the investigators.

Surveillance for diarrheal diseases in young children was undertaken in 411 households. Structured observations were conducted in 331 of these households; observations in the remainder were foregone either because a child was unwell, or for lack of time. Visits were prearranged. Field workers usually arrived by 9:00 a.m. and stayed until the child finished lunch, usually 1:00-2:00 p.m. In 170 of the 331 households (51\%), the index child was observed defecating during the visit. In 289 households, observations were made on excreta in the home environment while the observer was present.

\section{Research Initiative \#2}

The full methodology and results of this initiative are provided elsewhere (5). In brief, two communities representing a range of living conditions including type of housing, sanitary facilities, and terrain, were selected for study. Between August and November 1994, two local anthropologists conducted in-depth interviews with 69 mothers of young children. The mothers were selected on the basis of the location of their homes, number of children, the method of feces disposal employed, and the age and sex of their children. Interview guides were developed pertaining to each defecation method, based on findings from Research Initiative \#1 and of Huttly et al. (4), as well as to the respondents' general perceptions of feces. The anthropologists also interviewed nine husbands concerning their opinions on defecation practices. They explored the extent to which the men supported their wives, verbally or physically, in matters of hygiene. In addition, the anthropologists interviewed five community leaders to obtain information about the community, its priorities in terms of hygiene, efforts made to improve hygiene to date, opinions of feces disposal practices in the commu- nity, and the possibility of changing these practices. To validate information from the interviews and provide further insights into practices related to hygiene, the anthropologists conducted structured observations of mothers and their young children in 16 households. Eight households were visited on two occasions and eight on three occasions, always for approximately 4 hours in the middle of the day. Defecation by the index child was observed on 14 occasions.

\section{RESULTS}

\section{Perceptions of feces}

Information from both research initiatives showed that this population distinguishes feces according to whether they are from animals or humans and by their size and smell, which for humans reflects age and diet. Broadly speaking, five types of feces are recognized: from breastfeeding children, weaned children, adults, small animals, and large animals. Few people recognize that feces transmit disease. However, people often consider feces "dirty" because they attract flies, which are thought to carry microorganisms. The dirtiness of feces is partly determined by their fetor, which depends on a person's or an animal's diet. Feces of adults are considered dirtier than those of children because adults eat more, their stools are larger, and their stools have a stronger smell. Feces of young children, especially breastfed infants, are considered less dirty. Similarly, feces of larger animals such as dogs or pigs are considered more noisome than those of smaller animals such as chickens. Chicken feces are sometimes collected as fertilizer. These views are reflected in the quantitative results (Tables 1-3).

On arrival at each home in Research Initiative \#1, investigators made spot observations on the presence of excreta. Feces were present in a fair proportion of households (Table 1). During the subsequent 4-5 hour period, feces were deposited on the house 
TABLE 1. Spot observations of the presence of excreta in different parts of the home environment on the arrival of an observer (Research Initiative \#1). Peru, 1988

\begin{tabular}{lc}
\hline \multicolumn{1}{c}{ Location } & Percent of households with excreta $(n=331)$ \\
\hline Area where child seen on arrival & 12 \\
Special place for the child & 4 \\
Eating area & 16 \\
Kitchen & 15 \\
Latrine/feces pit $(n=197)$ & 31 \\
\hline
\end{tabular}

${ }^{\text {a }}$ For example, playpen, crib, or bed.

floor in $44 \%$ of households, in the yard in $69 \%$, and in the surrounding area in $47 \%$. In only $18 \%$ of households were no feces seen deposited during the observation period. Chickens and ducks were responsible for a large proportion of the defecation episodes, but dogs and humans also contributed, especially in the yard and surrounding area. Clearance of excreta was more common from the floor area than outside, but in the vast majority of cases the feces were left at least throughout the observation period (Table 2). Bird feces were less likely to be cleared than dog, cat, or human feces. In Research Initiative \#2, feces were seen in 10 of the 16 households $(63 \%)$ on at least one visit. The index child came into contact with feces on $15 \%$ of occasions that he or she had an opportunity to do so.

\section{Defecation sites and disposal of feces}

Disposal of feces in these shantytowns presents a number of problems. Because many houses are built on rocky terrain, a simple shallow pit with no ventilation pipe is generally the most feasible type of latrine. In the structured observations of Research Initiative \#1, about half of study households were observed to own such a pit; only a small proportion $(6 \%)$ owned a ventilated improved pit latrine. Many mothers complained about latrines, saying that they attracted flies and smelled bad. Kerosene was often used to mitigate both of these problems.
Parents do not favor their young children using latrines due to their general dislike of the smell and dirtiness, and for fear of "contamination." Much defecation by adults and older children was reported to take place out in the open in the nearby hill areas or other unoccupied areas. Children start to use these areas when they are about 3-4 years of age. Often an adult or older sibling accompanies the young child, but sometimes children go alone from a relatively young age. The hill is considered dangerous for children because of the risk of falling on the rocky paths. Several mothers reported that the hill may cause "supernatural" illness, stemming from the Andean belief that hills possess a certain force that may frighten people.

Very young children defecate around the home area. Many wear diapers (often made from cotton gauze), but these pose a problem, since water for washing them is scarce. Many mothers are anxious for their children to progress to methods other than diapers as quickly as possible. Of the 170 children observed to defecate in Research Initiative \#1, all those aged $<6$ months used diapers, and the proportion decreased to $14 \%$ in those aged $\geq 18$ months. Mothers considered potties the most desirable alternative for toddlers, whose feces are considered "dirtier" than infants'. However, some mothers reported that children do not like using potties and that it is difficult and time-consuming to persuade them to do so (5). No children aged $<6$ months were observed to use a potty, compared to $22 \%$ of those aged $\geq 18$ months.

Defecation sites become more scattered in the second year of life, when the infant becomes mobile. Stools are frequently deposited on the floor of the home or in the yard or surrounding area. Sometimes the child has a "set place" in these areas, in other cases defecation sites are clearly random. Mothers consider the former behavior to be much more acceptable than the latter. Twelve percent of defecation episodes of children aged 12-17 months occurred on the floor, yard, or surrounding area, and $48 \%$ in those aged $\geq 18$ months. "Defecation accidents" are quite common in these young children, and stools end up soiling clothes as well as diaper, floor, and potty. Altogether, there were 213 "defecation sites" in the 170 episodes, and what subsequently happened to the stool differed according to the site (Table 3). Stools passed on diapers or

TABLE 2. Clearance of feces according to the type of animal and location of deposit (Research Initiative \#1). Peru, 1988

\begin{tabular}{|c|c|c|c|c|c|c|}
\hline \multirow[b]{3}{*}{ Type of animal } & \multicolumn{6}{|c|}{ Area stools deposited } \\
\hline & \multicolumn{2}{|c|}{ Floor } & \multicolumn{2}{|c|}{ Patio } & \multicolumn{2}{|c|}{ Surroundings } \\
\hline & No. ${ }^{a}$ & $\% \mathrm{~b}$ & No. & $\%$ & No. & $\%$ \\
\hline Chickens or ducks & 107 & 12 & 132 & 1 & 59 & 0 \\
\hline Dog or cat & 8 & 12 & 24 & 8 & 74 & 4 \\
\hline Human & 12 & 50 & 26 & 12 & 51 & 6 \\
\hline
\end{tabular}

a Number of households where stool type was deposited during the observation period.

${ }^{b}$ Percentage of households where stools that had been deposited were cleared during the observation period. 
TABLE 3. Final destination of stools by site of deposit (\% of defecation occasions) (Research Initiative \#1). Peru, 1988

\begin{tabular}{lrrrrr}
\hline & \multicolumn{5}{c}{ Site of stool deposita $^{\mathrm{a}}$} \\
\cline { 2 - 6 } Final destination & Diaper & Clothes & Floor & Yard & Potty \\
\hline Left $^{\mathrm{b}}$ & 6 & 22 & 46 & 73 & 23 \\
Kept $^{\mathrm{c}}$ & 79 & 48 & 0 & 0 & 0 \\
Floor & 0 & 0 & 0 & 0 & 0 \\
Yard & 0 & 2 & 9 & 7 & 0 \\
Surroundings & 1 & 4 & 18 & 7 & 23 \\
Rubbish & 1 & 2 & 9 & 7 & 8 \\
Latrine & 0 & 2 & 0 & 7 & 31 \\
Washed & 13 & 12 & 9 & 0 & 0 \\
Others & 0 & 0 & 0 & 0 & 8 \\
Missing information & 0 & 8 & 9 & 0 & 8 \\
$\quad$ Total & 115 & 50 & 11 & 15 & 13 \\
\hline
\end{tabular}

a In addition to the sites listed here, stools were also deposited in nine unlisted "other" sites.

${ }^{b}$ Left where the stool was initially deposited.

${ }^{c}$ When the soiled diaper or clothing was put to one side with other clothing.

clothes were most likely to be left where deposited or kept to one side for later washing. Those passed in potties were usually thrown in the latrine or the surrounding area.

\section{Cleaning after defecation}

Mothers spoke of the importance of handwashing after defecation, changing diapers, or cleaning a child who has defecated. However, few were seen to wash their hands during the observations. On only $5 \%$ of occasions were children's hands washed. The child's bottom was cleaned on $95 \%$ of occasions (varying from $100 \%$ in children aged $<6$ months to $84 \%$ in those aged $\geq 18$ months), almost always by the mother. The cleaning methods included wiping the child's bottom with his or her diaper $(65 \%)$ and/or clothes $(20 \%)$ or paper $(11 \%)$. The child was washed with water alone in $12 \%$ of cases and with water and soap on $7 \%$. The cleaning material was usually left dirty; only $7 \%$ of diapers were put in water to soak, and only $4 \%$ washed with water and soap. In $61 \%$ of cases where paper was used, it was discarded either in the rubbish bin or a potty or the latrine. Where water was used, it was usually either kept or thrown onto the surrounding floor/ patio. After cleaning, $70 \%$ of children were visually clean of feces. Twentyone percent had traces of feces on their body, and $8 \%$ on their clothes. Eighty percent of persons who washed children did not wash their hands after doing so. Ninety percent of those who washed their hands washed ineffectively (i.e. not washing the whole hand using clean running water and soap).

\section{DISCUSSION}

This study contributes to a small but growing literature on stool disposal, and illustrates the use of a combination of methods for describing and quantifying existing practices. The results shed light on the range of practices for disposing of stools from children and adults in an urban shantytown in Peru, as well as how the practices vary ac- cording to the age of the defecator. They confirm expectations that environmental conditions in Canto Grande make hygienic disposal of feces problematic in this community.

The construction of a conceptual framework based on existing feces disposal behavior is a key step in designing an appropriate intervention to improve methods of feces disposal. Despite the obvious environmental difficulties, some attitudes and practices in Canto Grande could provide the basis for promotions that could lead to a greater overall level of hygiene related to feces disposal. One practice that may be profitably promoted is the expanded use of potties. We have conducted a small-scale trial of promoting and improving the use of potties, and found that an intervention addressing this issue was both feasible and acceptable to the community (5). A large-scale community trial is currently underway.

The finding that feces of young children were not felt to be as dirty or dangerous as those of adults or older children has been encountered elsewhere $(6,7)$. This may partly account for the low rates of handwashing after cleaning a child who had defecated. The perceptions of feces and "dirtiness" found here will aid in the formulation of messages for planned interventions to improve hygiene related to the disposal of feces, including the use of appropriate terminologies.

Acknowledgments. Research Initiative \#1 was funded by the Program for the Control of Diarrheal Diseases of the World Health Organization, and the Thrasher Research Foundation. Research Initiative \#2 was funded by the United Kingdom Overseas Development Administration. We are very grateful to the field workers of the study for their dedicated work and to the study households for their participation. 


\section{REFERENCES}

1. Esrey SA, Feachem RG, Hughes JM. Interventions for the control of diarrheal diseases among young children: Improving water supplies and excreta-disposal facilities. Bull World Health Organ 1985;63(4):757-772.

2. World Health Organization. Improving water and sanitation hygiene behaviors for the reduction of diarrheal disease: The report of an informal consultation. Geneva: WHO; 1993. (WHO/ CWS/90.7, WHO/CDD/93.5).

3. Lanata CF, Black RE, Gilman RH, Lazo F, del Aguilar R. Epidemiologic, clinical and laboratory characteristics of acute vs. persistent diar- rhea in periurban Lima, Peru. J Pediat Gastroenterol Nutr 1991;12:82-88.

4. Huttly SRA, Lanata CF, Gonzales H, Aguilar I, Fukumoto M, Verastegui H, et al. Structured observations of handwashing and defecation practices in a shanty town of Lima, Peru. J Diarrhoeal Dis Res 1994;12(1):14-18.

5. Yeager BAC, Huttly SRA, Bartolini R, Rojas M, Lanata CF. Defecation practices of young children in a Peruvian shanty town. (Submitted for publication) Soc Sci Med.

6. Zeitlyn S, Islam F. The use of soap and water in two Bangladeshi communities: Implications for the transmission of diarrhea. Rev Infect Dis 1991;13(suppl 4):S259-S264.

7. Curtis V, Kanki B, Mertens T, Traoré E, Diallo I, Tall F, et al. Potties, pits and pipes: Explaining hygiene behavior in Burkina Faso. Soc Sci Med 1995;41(3):383-393.

Manuscript received on 5 May 1997. Revised version accepted for publication on 24 April 1998.

RESUMEN La disposición sanitaria de las heces es indispensable para poder combatir la diarrea de la infancia y su promoción es esencial para mejorar la salud en países en desarrollo. Es necesario conocer las prácticas actuales de disposición de excretas a fin de formu-

Heces, moscas y hedor: resultados observados en un barrio pobre del Perú lar estrategias de intervención eficaces. Dos estudios se llevaron a cabo en un barrio pobre de Lima, Perú. En el primero se recolectó información por medio de entrevistas minuciosas a madres y observaciones estructuradas (4 horas) de niños pequeños y sus responsables. Se obtuvieron datos sobre las creencias y prácticas vigentes con respecto a la disposición de excretas. En $82 \%$ de los domicilios observados, se encontraron excretas depositadas por animales o seres humanos dentro o en el exterior. Las creencias en torno a las heces dependieron de su origen y se vieron reflejadas en las posibilidades de que las heces fueran recogidas. Aunque se observó que $22 \%$ de los niños de 18 meses o más defecaban en un recipiente, $48 \%$ defecaban en el suelo, donde las heces a menudo se quedaban. Pese a que a casi todos los niños los limpiaron después de defecar, 30\% siguieron teniendo materia fecal en el cuerpo o en la ropa. Los niños $(5 \%)$ o sus responsables $(20 \%)$ raras veces se lavaron las manos después de la defecación del niño. En este tipo de comunidad, la disposición sanitaria de las heces plantea un problema. No obstante, se observaron algunas prácticas que apuntan a que en un futuro su promoción, incluido el uso de un recipiente, será más amplia. 